\title{
Using Mobile Devices for Teaching Realistic Mathematics in Kindergarten Education
}

\author{
Nicholas Zaranis ${ }^{1}$, Michail Kalogiannakis ${ }^{1}$, Stamatios Papadakis ${ }^{2}$ \\ ${ }^{1}$ Department of Preschool Education, Faculty of Education, University of Crete, Crete, Greece \\ ${ }^{2}$ Ph.D Candidate, Secondary Education Teacher, Crete, Greece \\ Email: nzaranis@edc.uoc.gr, mkalogian@edc.uoc.gr, stpapadakis@gmail.com
}

Received April 16 $6^{\text {th }}, 2013$; revised May $17^{\text {th }}$, 2013; accepted May $24^{\text {th }}, 2013$

Copyright (c) 2013 Nicholas Zaranis et al. This is an open access article distributed under the Creative Commons Attribution License, which permits unrestricted use, distribution, and reproduction in any medium, provided the original work is properly cited.

\begin{abstract}
New ICT tools allow children to take advantage of new learning platforms as well aiding them effectively in attaining new knowledge through activities related to their immediate interests and real life scenarios. Nowadays, computers and digital applications are a part of the daily life of children. In kindergarten education, properly designed digital educational activities can become a very powerful educational tool for efficient and effective learning. The utilization of interactive activities may contribute towards the growth of learning incentives as well as proper mental development in particular areas; such as mathematics and science. Mobile devices have new attractive features and provide considerable advantages in the teaching of mathematics in kindergarten education. Our study proposes the integration of mobile devices, running our own specially designed learning activity applications, in kindergarten classrooms. These applications are based on the three levels of Realistic Mathematics Education (RME) targeting fundamental mathematical concepts for the kindergarten level. We intend to gather information on effectiveness of the incorporation of these devices and applications as leaning tools for kindergarteners.
\end{abstract}

Keywords: Preschool Education; ICT; Mobile Learning; Digital Learning Activities; Realistic Mathematics

\section{Introduction}

The introduction of ICT (Information and Communication Technologies) in the field of Preschool Education has been a point of debate and controversy among researchers for an extended period of time. Due to the highly dynamic introduction of computers in the educational reality among the Western society and the influence of related research, computer aided learning is more realistic than it once was; thus gradually replacing any initial resistant reactions towards the use of ICT in a learning environment. A wide variety of ITC applications have become increasingly accepted as developmentally appropriate education resources for children of preschool and primary school age (Druin \& Fast, 2002; Plowman \& Stephen, 2003; Zaranis \& Kalogiannakis, 2011a; Zaranis, 2012).

Moreover, modern researchers have expanded the content of the term ICT to deal not only with the desktop computer but well as mobile technologies embedded in various devices (Plowman \& Stephen, 2005; Gjelaj, 2013) such as e-toys, digital cameras, smart games, electronic tables and smart mobile devices (Voithofer, 2005). Via the Internet, children are now able to surf and search for information, play games, watch videos and even make use of numerous online services such as making and receiving VoIP calls using Skype. There have even been reported cases of kindergarten children creating and maintaining their own blog and engaging in online social networking. Now digital media and interfacing with new technologies is a part of day-to-day life for children of all ages (Fi- nitsis, 2012)

Computers not only isolate children but also act as a catalyst in their social interaction and provide children with additional opportunities for rich learning activities that are relevant to their growth characteristics regardless of age. International research studies (Yelland, 2002; Druin \& Fast, 2002; Plowman \& Stephen, 2003; Musawi, 2011; Zaranis, 2011; Zaranis, 2012) on the introduction of computers in preschool education show that computers in the classroom have positive results in regard to the learning of different subjects.

ICT can play an essential role in achieving the goals of the kindergarten curriculum in all areas and subjects (Plowman \& Stephen, 2003; Chronopoulou \& Riga, 2012) if the provided developmentally appropriate software applications (Haugland, 1999; Lee, 2009) are embedded in appropriate educational scenarios (Zaranis \& Kalogiannakis, 2011b). In addition to the educational purpose, the use of computers in kindergarten is characterized mainly as a learning activity while the common child will see it as a game of sorts. Like many researchers, in formal and informal settings, we strongly endorse the need to focus our investigations on meaningful learning through playing. It is now clear that the use of this learning process is more than adequate in achieving given educational goals for children at the preschool and primary school levels (Plowman \& Stephen, 2005; Zaranis, 2012).

In the classroom, ICT is treated as a learning tool (Zaranis \& Kalogiannakis, 2011a). For the students, ICT is a means for achieving familiarity with new technologies as well as being a 
tool of investigation, communication and understanding across the full range of the curriculum.

In recent years, with the emergence of smart mobile devices, several researchers (Lam \& Duan, 2012) have proposed the use of mobile devices for learning. There are multiple advantages with respect to the use of said devices in the learning process including stimulus, motivation, ease of use, availability, etc. (Vavoula \& Karagiannidis, 2005). Such devices are becoming highly valuable tools in the educational process because of their attractive features (Klopfer, Squire, \& Jenkins, 2002). Mobile devices are portable, more affordable, in relation to desktop computers, offer the opportunity for learning without local restrictions, use the possibilities offered by the wireless mobile technologies for easy access to information, promote the development of digital literacy, provide opportunities for independent learning, facilitate people with disabilities etc.

Shuler (2009) stated that applications on smart mobile devices have the potential to become the new means of providing educational content to students. As mobile technologies play an increasingly prominent role in the lives of children worldwide, national ministries and schools are experimenting with the use of these popular devices for a wide range of alternative methods of teaching and learning objectives. Smartphones and tablets are among of the six new emerging technologies that may have a major impact on teaching, learning, and research in primary education (Johnson, Smith, Willis, Levine, \& Haywood, 2011).

Particularly in the subject matter of mathematics, Zaranis (2011) made a comparison between the learning outcomes of computer based teaching and mathematical thematic teaching; more specifically, targeting the teaching of "Realistic Mathematics" for children ages 4 to 6 years old in Greek Kindergarten. Compared to the traditional thematic teaching method, results showed that computer-assisted learning may significantly enhance the development of mathematical skills and the cultivation of a deeper perceptual ability for the pupils (Zaranis, 2011; Zaranis \& Kalogiannakis, 2011b).

The main purpose of this study is to provide a better understanding of the characteristics and the effect of ICT, especially mobile learning, in the context of kindergarten education. We will try to achieve the above through a systematic literature review on the introduction and use of ICT and smart mobile devices in kindergarten education. In particular, we will study the use of educational applications in the form of digital activities for preschool education. This paper will also present the first phase of an instructional intervention that utilizes a series of educational applications designed according to the principles of Realistic Mathematical Education. Our research materializes in the form of digital activities performed on smart mobile devices. These activities consist of comparison, sorting, matching, structured counting, efficient counting and the general knowledge of numbers exercises.

The originality of this work lies in the fact that it is the first study carried out in the field of kindergarten education in Greece. It attempts to take advantage of the children's existing familiarity with the use of smart mobile devices (tablets) to provide a benefit to the learning process. In the context of this document, a detailed and systematic effort will be made towards achieving a theoretical justification for the implementation of reformed teaching proposals.

\section{ICT and Children as "iLearners"}

Researchers Christie and Johnson (2009) indicate that digital media has now permanently settled in the lives of young children. As pointed out by Lavidas, Komis, \& Gialamas (2012), many times children surpass adults in their modern technological knowledge even before attending kindergarten. Hertzog and Klein (2005) define a distinct line between the current generation of children and their parents. They very aptly report that children do not need to adapt to the new technological society because they were born in it; unlike their parents who have acquired their technological knowledge as somewhat of a foreign language at an advanced age. Consequently, according to Prensky (2001), young children can be described as "digital natives" since they are growing up in the digital world. Most recently, Prensky (2010) refers to today's students as “iLearners" deriving from the fact that digital devices such as smartphones and tablet computers dominate the daily lives of children in Western societies from the age of 6 months.

The Lieberman, Bates and So (2009a) report that several studies have shown that digital media can introduce children to abstract concepts that were previously considered too advanced for their age. In her research, Yelland (2005) has shown that activities entailing the use of digital media, within the school environment, facilitate collaborative learning for young children and the development of logical thinking while reinforcing their ability to solve problems. Digital learning activities may encourage children to work together. They have been found to be more effective than traditional learning activities (Zaranis, 2011; Zaranis \& Kalogiannakis, 2011a).

Young children have access to new technologies not just in the school environment but also out of school, at home (Plowman \& Stephen, 2005; Somekh, 2007). For some children, the first educational experience with computers begins in the kindergarten age, between 4 to 6 years old. Existing studies have shown that children of this age can successfully handle computers with the appropriate instruction (Zaranis, 2011; Zaranis \& Kalogiannakis, 2011a). In a study of the comparison between learning at home and in the kindergarten classroom, Plowman, Stephen and McPake (2010) found out that ICT is used to promote three main areas of learning. The extension of knowledge about the world (cognitive objects), the acquisition of functional skills (such as the operation of the mouse) as well as the development of the propensity for learning (by strengthening a range of emotional, social and cognitive functions of learning).

Recent studies have identified a number of emerging digital devices, such as tablets, as being appropriate for the education and entertainment of children (Verenikina \& Kervin, 2011). Lieberman et al., (2009a) commented that young children age three to six years old play with a vast variety of digital learning activities, now available on desktop monitors and portable screens, spending a constantly increasing amount of time doing so.

Furthermore, Couse and Chen (2010) state the advantages offered by the use of mobile devices with touch screens compared to typical computer applications controlled by a mouse. The significant potential offered by tablets should also be noted, as they are not only useful and portable, but also more affordable compared to laptops (Leoni, 2010). The acquisition cost of applications is very competitive and often includes the ability of a user to download a "light," often free, or trial version of applications. Fuegen (2012) identifies tablets as compact laptops with optimized operating systems, devoid of a physical keyboard, however, provide interactive capabilities via built-in functionality and the use of third party applications (mobile 
apps). Similarly, the term smartphone describes mobile phones which, besides the usability of voice data over cellular networks, have similar features and characteristics of tablets but with a smaller screen size.

Orlando (2012) commented that portable devices fit perfectly in the lifestyle of young children as they do not need to sit at a table or an office to use the device, they do not need to handle a mouse, while the interface offered with a single touch on the touchscreen is irresistible. Children now use the new technology at a younger age than ever before (Common Sense Media, 2011). A study including Australia, New Zealand, USA and Great Britain showed that most children ages two to five years are more able to interact with a tablet than to tie their shoes (Orlando, 2012). Moreover, the possession of smart mobile devices by children ages four to fourteen years old has doubled since 2005 (NPD Group, 2008).

According to a survey by the MDG Advertising Company (2012), preschoolers today make use of mobile devices more than ever in the past. The same survey indicated that more than half of all first time iPad and iPod device users are children under the age of five. However, not all researchers explicitly support the use of smart mobile devices by young children. Banister (2010) notes the lack of research on the use of tablets in education as they have only recently been introduced into the market. In addition, Marsh (2010) advocates the "dichotomy" that arises between the activities at hand and the technology supporting it. He claims that the emerging phenomenon of "digital activities" differs from that of the spontaneous children's play because the digital activity depends largely on, and is often limited by, the actual design of the software and hardware.

\section{Learning via Mobile Devices}

Sharples, Taylor and Vavoula, (2007) define mobile learning as any kind of learning that takes place in learning environments and areas which take into account the mobility of technology, the mobility of learners and the mobility of learning. Mobile learning through the use of tablets and smartphones presents new opportunities for strengthening the learning experiences in ways that simply other devices cannot achieve (Lam \& Duan, 2012).

High-resolution screens allow tablet users to share static content and resources such as images and videos in an easy way. Most tablets have no phone features making them ideal tools for education since disruptive elements for the learners' attention such as incoming text messages or unwanted calls that are present in phones and smartphones alike, are absent. Tablets are able to offer the benefits of mobile applications in a broader context in all levels of education, not only as an affordable solution for one-to-one learning but also as a feature rich tool for work inside and outside the classroom.

Wakefield and Smith (2012) indicate that the technological analysts characterize the tablet as an ideal tool for all levels of education. After the introduction of tablets in the classroom of several schools in the United States, students report that they want to participate in learning activities due to the novelty of the medium, the visual characteristics and ease of use. In the classroom, tablets can be used to create text, audio or video notes. Students, independent of age, can store educational materials in a digital portfolio. Using a tablet, learning can be achieved through the active participation of students and the use of interactive activities and animations. Additionally, the attractive appearance of the working environment and the innovative touch interface are considered key learning facilitators for young children and students with learning disabilities. The characteristics of tablets including light weight, portability, touch screen, large icons, speakers, voice commands, zoom features and the cognitive simplicity are some of the key advantages that make them an affordable and more than efficient tool for the education of young children (Buchanan, 2010).

At least 1000 universities and colleges create and distribute free educational content in a format suitable for reproduction on smart mobile devices (MDG Advertising, 2012). According to McManis and Gunnewig (2012), this fact creates new requirements from the devices users as well as other opportunities for innovative services through these devices.

Several governments worldwide have given special attention to the development and implementation of mobile learning in order to improve teaching and learning effectiveness. Lam and Duan (2012) state that pioneers in this initiative are not only the governments of developed countries but also of developing countries that have begun to adopt policies and measures for the development of mobile learning. Characteristically, they indicate that the Royal Thai Government plans to provide tablets to 800,000 students of all educational levels by the next school year. As early as 2011, an initiative of the Indian government was to build the cheapest tablet in the world. It was sold to students at a subsidized price of 35 dollars, implementing the transition from the traditional to mobile learning in a faster and easier way. Simultaneously, the Turkish government announced that it plans to spend 8 billion dollars for the purchase of 15 million tablets, which will be distributed among school-age children throughout the country.

Finally, as reported by Kenny and McDaniel (2011), while overcoming past misconceptions that perceived the use of technology only as electronic gaming and play among students, many teachers and schools united are beginning to allow students to bring their own smart mobile devices into the classroom; especially since recent studies have shown that video games, including learning activities, have become an integral and essential part of the way in which young people learn.

\section{Mobile Devices in Kindergarten Education}

Egan and Hengst (2012) show that, even though educational software has been available almost 30 years now, the educational community of kindergarten education initially resisted the use of computers in the teaching of young children. Many educators, inspired by Piaget's theory of the developmental stages of children, considered that young children need only the physical activity and the ability to handle tangible objects in order to consequently achieve understanding of the various abstract concepts. However, since the mid-1990s, researchers found that virtual manipulations which are facilitated by computer software are similar to physical manipulations and therefore, the use of ICT could effectively support the learning process, particularly in mathematics, and the educational development of children as a whole (Yelland, 1998; Clements, 2000).

Nowadays, the use of ICT in the education of young children, as well as the development of educational software and relevant activities in preschool education, has already spread in many educational systems (Druin \& Fast; 2002; Plowman \& Stephen, 
2003; Zaranis, 2011; Zaranis, 2012). Research results point out the potential of ICT as a teaching tool (Segers \& Verhoeven, 2005) and as a cognitive tool (Clements, 2000; Klein, Nir-Gal, \& Darom, 2000). Such results seem to formulate a common agreement at the level of educational policy and school practices that promote the rational integration of ICT in early childhood education (NAYEC, 1996; Yelland, 2002; Plowman \& Stephen, 2003; Bolduc \& Lefebvre, 2012). Several studies indicate that computers are developmentally appropriate technological resources for pupils of preschool and primary school education and show how technology can be used to support and encourage the development and learning in these age groups (Musawi, 2011; Zaranis \& Kalogiannakis, 2011a).

The integration of mobile devices into the preschool curricula aims at strengthening the interest of young learners and in enhancing their participation and cooperation with their classmates and teachers (Lindahl \& Folkesson, 2012). According to Nix (2005) this type of learning attracts the interest of young students and it is considered both an enjoyable experience and an attractive learning environment. Rushton, Juola and Larkin (2009) point out the need for proper learning conditions and indicate that children learn more easily in positive and encouraging learning environments. These said learning environments allow the students to make their own decisions regarding which topic to study out of their own free will. Rushton (2008) states that the creation of a classroom environment that enhances student expression and selection opportunities provides a welcoming atmosphere towards helping children to learn at their own pace. Learning environments, which through various mediums provide differentiated teaching to young learners, allow children to be actively responsible for their learning, by simultaneously stimulating various areas of their brain thus resulting in better intellectual development (Rushton \& Larkin, 2001).

The portability of tablets allows children and kindergarten teachers to make use of various locations in the classroom enabling the creativity and collaboration of small groups of students. Additionally, the sophisticated user interface of tablets allows both individual interaction and often, mutual interaction, depending on the application at hand, between two or more children (Wakefield \& Smith, 2012).

Research findings (Abrams, 2009; Jenkins, 2009; Dickens \& Churches, 2011 as cited in Peluso, 2012) correlate the effecttiveness of learning through educational content delivery based on touch screen technology. A study by Chiong and Shuler (2010) in the United States involving iPod touch devices and audiovisual material properly configured for children ages three to seven years old showed that children drew remarkable gains in vocabulary and phonological awareness. Another recent survey by Bebell, Dorris and Muir (2012) on kindergarten students selected randomly to use tablets for the study of literacy, showed that infants who used tablets recorded remarkably strong performance in their phonological awareness and their ability to represent sounds with letters in relation to other children that did not.

Sandvik, Smørdal, and Østerud (2012) point out that as well as tablets are highly portable technology, learning can take place in a variety of everyday activities in the kindergarten, in a formal and informal context, inside and outside the classroom. As reported by McManis and Gunnewig, (2012), the new digital tools, such as smart mobile devices and their accompanying applications, can offer unique opportunities for kindergarten children to participate in useful and targeted activities; either individually or collectively with their peers and their kindergarten teachers.

\section{Digital Activities and Children}

The introduction of smart mobile devices in the daily life of children positively supports integration of digital applications in childhood education. There is a positive continuum between the everyday life of children and their school life. Moreover, it is important that the technological instruction offered by the school equips children with the necessary knowledge and skills for later life as well.

Digital learning activities on mobile platforms are very popular among students, especially at younger ages. Particularly, in the last few years, the accession bid of educational digital activities as teaching tools in the educational process has increased. The term electronic or digital activity refers to all categories of activities that are implemented through digital technology. It concerns activities and games that run on large classic game consoles, specialized consoles, personal computers, smartphones and tablets (Chiong \& Shuler, 2010). Researchers such as Klein et al., (2000), Lewin (2000), Segers and Verhoeven (2005), Comaskey, Savage and Abrami, (2009), Zaranis and Kalogiannakis (2011b) document the positive impact of digital applications in the educational development of preschool age children. Other studies show that electronic activities and games attract children and seem to stimulate them in a more constructive manner than the standards the conventional education has adopted so far (Klawe, 1999; Prensky, 2001; Zaranis \& Kalogiannakis, 2011a).

Since the early 1990s, the trend has been that of edutainment. This refers to the blend of gaming and educating based on the logic of activities developed with clear educational orientation (Shaffer, Squire, Havelson, \& Gee, 2005). The contribution of digital activities lies in the fact that they allow children to participate in worlds in which they learn to think, speak and act in new ways. Being rich in features, these virtual worlds constitute a very promising framework for learning, as children can play many different roles (Squire \& Jenkins, 2003; Shaffer et al., 2005; Squire, 2006). Digital activities are considered to be particularly effective when they are designed to examine a specific problem or to teach a specific skill. For example, encouraging learning in the thematic areas of the curriculum such as mathematics, natural sciences and language where the specific objectives can be determined and when it is selectively developed within a context relevant to the learning activity and the specific target (Johnson et al., 2011).

For children aged three to five years old, educational digital activities often focus on readiness skills for the kindergarten, including reading (letter recognition, letter formation, correlation of sounds and letters, simple spelling), mathematics (recognition of numbers, formation of numbers, counting, grouping), thinking and reasoning skills, perceptual skills, daily life skills (hygiene), social skills, creativity and self-expression; as well as the understanding of concepts such as family relations, emotions, professions, etc. (Lieberman, Fisk, \& Biely, 2009b).

Lieberman et al., (2009b) distinguish the quality of digital learning activities in the following categories:

- Well-designed activities - provide powerful interactive experiences which can enhance the learning of young children, fostering skills development, as well as their healthy development; 
- Poorly designed activities_-simple sedentary activities that contribute little in children's learning, skills development or their healthy development while potentially associated with obesity and poor physical condition;

- Very poorly designed activities - can potentially cause considerable damage to children either through strengthening the aggressive or antisocial behaviour, approbating ethnic or transgender stereotypes and promoting bad eating standards.

A finding of several studies in children three to six years old correlates the benefits of using digital activities in different sectors (Figure 1).

More specific benefits are identified in the following sectors:

- Learning-Digital activities can provide considerable educational services to children. Comparative studies have suggested that well-designed educational activities provide potentially more motivation and result in encouraging learning compared to traditional teaching methods (Swing \& Anderson, 2008);

- Cognitive skills-Using digital activities, children learn cognitive skills through repetition, as relevant studies have found improvements in operating memory, spatial ability, visual attention, etc. (Thorell, Lindqvist, Bergman, Bohlin, \& Klingberg, 2009);

- Social interaction-In preschool education, young children often engage in cooperative social interaction when playing digital activities (Christie \& Johnson, 2009).

If materials for play and learning (including computer activeties) are designed to indulge the interests and abilities of children, as well as their instinct to learn, students are more likely to develop and strengthen their initiative, their attention, their industriousness and their love for learning (Kagan \& ScottLittle, 2004; Sadowski, 2006).

However, as pointed out by Garrison and Christakis, (2005) not all digital activities are developmentally appropriate or meticulously designed to enhance the procedure according to which young children play and learn.

\section{Realistic Mathematics}

The foundations of children's mathematical thinking form in the early years of their life. They gradually acquire their first experiences with time and space then with basic mathematical processes (measurement, calculation, sorting and comparison) (Gadzichowski, 2012). Research findings prove the existence of logical principles for counting from the age of three (Gelman \& Meck, 1983). Other researches indicate that numbers and numerical phenomena sparks the intense interest of children from an early age (Zaranis \& Kalogiannakis, 2012). Mathematics in preschool education is approached as a foundation that will help children learn about the world around them and to adapt to this world (Tzekaki, 2007; Zaranis, 2012). Egan and Hengst

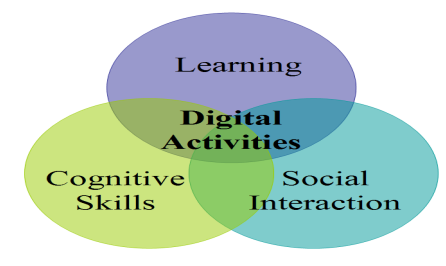

Figure 1.

Benefits of the use of digital activities by young children.
(2012) report that a large body of research shows that the time spent in the kindergarten is a crucial period for children to develop fundamental numeric skills. In their research on the development of mathematical concepts in kindergarten, Clements and Samara (2007) concluded that the numerical abilities of children, developing before they enter the first grade of primary school, are the best predictors of their subsequent mathematical progress; more than other skills. When monitoring 200 students from the kindergarten up to the third grade, Jordan, Kaplan, Ramineni and Locuniak, (2009) concluded that the conquest of mathematical concepts in the kindergarten is positively correlated with the achievement of high mathematical performance at the end of the third grade.

Consequently, the teaching of mathematical concepts in the kindergarten has a huge significance, as it assists children to acquire the necessary mental condition and the necessary cognitive foundation for the systematic learning of "real" mathematical concepts, later on, in primary school. The aim of kindergarten is not just to teach mathematics but to initiate children in ways of thinking that characterize the mathematical science while providing a parallel realization of their social dimension.

For many years, the central theme for scientific debate was the formulation of a comprehensive mathematical theory towards interpreting phenomena related to the teaching and learning of mathematics. Such a theory aimed to provide educators with the ability to help students understand mathematics as a subject and as a tool for solving everyday problems. Over the last few years and in the context of the above considerations, various reform proposals for the teaching of mathematics have been developed internationally, posing their focus on the problem solving procedure. One of these proposals is the Realistic Mathematical Education (RME) which was developed in the Netherlands and supports the view that the same phenomena through which the mathematical concepts acquire content, should be used as a basis for a teaching process that aims to impart these concepts (Freudenthal, 1983).

According to Freudenthal (1983), mathematics is a human activity and therefore it must constitute a human value, must be close to reality of fact, be close to children and have a relationship with society. The central idea of the Realistic Mathematical Education is when saying, "I know math" really means "I know how to do math” (Streefland, 1991). The student becomes able to easily handle the mathematical language, to solve and construct problems, but mainly, to recognize mathematical concepts within specific situations. The term "Realistic Mathematics" refers to mathematics, which relate to problems of the real world as well as to phenomena, which appear in our daily life (De Lange, 1996). This form of mathematical education is characterized as "realistic" because it relates to the real world, in addition, to that special emphasis given in situations in which the students can envisage with their imagination.

The digital learning media can contribute to the learning of mathematical concepts by young children. Many aspects of early informal learning of mathematical concepts, such as enumeration, arithmetic problem solving, and spatial syllogism along with general geometrical knowledge, are developed dramatically during the preschool age. Therefore, digital technologies and accompanying software that teach early learning of mathematical concepts have received considerable attention from the scientific community (Lieberman et al., 2009a). The use of mathematics-related computer programs in preschool 
children leisure activities enhanced the mathematical knowledge of those children (Starkey, Klein, \& Wakeley, 2004). Jordan et al., (2009) report in a similar study, that young children were able to develop mathematical skills and relevant reasoning and thinking skills while using developmentally appropriate mathematical software.

Today, the use of mathematical technology in kindergarten education and the first primary grades is a standard. It is included as one of eight Standards for Mathematical Practice in the Common Core State Standards for Mathematics (Common Core State Standards Initiative, 2010). The principles that underpin the Realistic Mathematical Education constitute a framework in which technology could offer significant assistance in the teaching and learning of mathematics (Clements, 2000).

\section{A Proposal for Teaching Realistic Mathematics through Mobile Devices}

Currently, within the Faculty of Education, Department of Preschool Education, University of Crete, systematic research is being carried out in order to investigate whether there are compelling benefits to using tablet computers in preschool education in an attempt to implement teaching reform proposals, such as Realistic Mathematical Education and the Natural Sciences. This proposition is carried out by creating educational applications for the mobile device platform in the form of digital learning activities, using specialized software (App Inventor). These applications intend to help preschool children in learning mathematics by following the principles of RME, focusing primarily on the existence of rich thematic frameworks associated with a child's experiences. For this reason, digital applications are combined with group and individual activities without the use of a tablet including board games, dice, activeties with given and hidden objects, etc. This form of digital application was chosen because studies (Nix, 2005; Vavoula, Pachler, \& Kukulska-Hulme, 2009) have shown that digital educational activities are not only appealing to the students' interest but are also considered to be a pleasurable pastime while establishing a new and attractive learning environment. Today's students are more likely to enjoy a learning experience embedded with digital activities because these games are based on the primordial form of learning "play and learn" from which they derive their benefits as an educational tool (Squire, 2006).

Specifically, we have developed sixteen different activities that cover four levels of mathematical intervention (ground or zero, first, second and third) based on the principles of RME for preschool education (Van Den Heuvel-Panhuizen, 2008; Zaranis, 2011, 2012). The purpose of the next step of the research is to extensively implement such applications and other educational activities in kindergarten classrooms in order to systematically evaluate their integrity and educational use compared to the traditional method of teaching.

According to Van Den Heuvel-Panhuizen (2008), the knowledge of formal mathematical concepts may differ considerably from child to child when entering into kindergarten. To elaborate, some of these children are quite familiar with simple counting while other children are not. Likewise, the extents to which they are capable of distinguishing between the different meanings of numbers may vary. The understanding of resultative counting children have developed upon entering to kindergarten differs significantly too. The somewhat variable initial situation in which the children's different initial levels of mathematical knowledge upon beginning the kindergarten could be described as the ground level. In general, an elementary numerical sense develops before and during the preschool education, in four general levels (Figure 2).

In addition to the pre-existing ground level, the three general levels that are developed during kindergarten education are as follows:

- First level-The level of context-bound counting and calculating simple addition and subtraction;

- Second level-The level of object-bound counting and calculating simple addition and subtraction problems where the objects are displayed and then hidden;

- Third level-The level of pure counting and calculating addition and subtraction with the use of a missing variable.

The first level consists of context-bound situations in which pupils are instructed to count up to ten, organize numbers in the proper order, and make reasonable estimations or comparisons of numbers through concepts of more than, less than or equal too. Basic addition and subtraction problems are introduced at this level.

The relevant object-bound counting and calculating of the second level, which occurs in problem situations, focus directly on the quantitative aspect. In contrast to the first level, questions asking that the students count and state the number of given objects, in a given scenario, are presented and understood in the second level. This applies, however, only if the questions asked are associated with specific objects involving natural numbers. The second level also consists of activities in which pupils able to choose an appropriate strategy for solving simple addition and subtraction problems in which the objects at hand are displayed for a brief period of time before they are hidden. The following are several examples of level two questions: How many pieces of candy are in the box? How many chairs are there? How many people are waiting in line? Which box has the most sweets? How many of the seven candles will remain lit if the wind blows out three?

Finally, the third level consists of pure counting and calculating, questions using real numbers, rather than objects, focusing on the aspect of a missing variable. For instance, "What will remain if you subtract three from seven?” By previously hiding objects after a brief period of time (second level), children were obliged to use their fingers or other representations for more the complex tasks as the visual objects were being removed from the equation. This way, the enumeration is no longer dependant on the objects themselves, and is instead put into perspective using physical or mental representations of these objects. These representations can occupy different levels of abstract problems including the use of real numbers in addi-

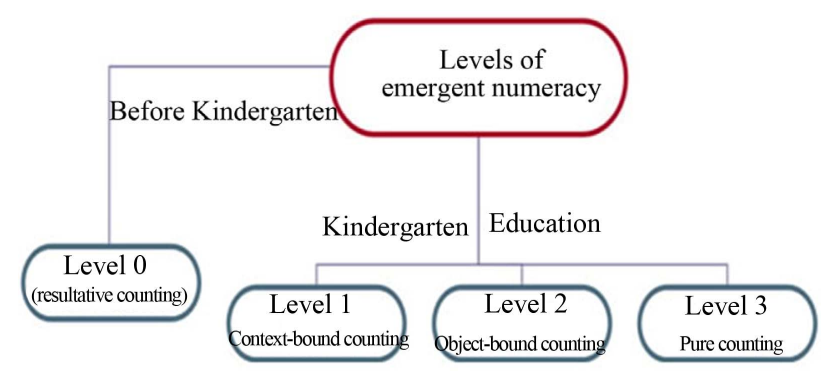

Figure 2.

Levels of realistic education in kindergarten education. 
tion and subtraction problems with a missing variable.

As Van Den Heuvel-Panhuizen (2008) claims, this can occur by using a "birthday hat" but there are other possibilities, such as the kindergarten teacher asking the children to describe their age without using words. At the third level, children can represent the numbers one to ten using their fingers, as well as by using lines and dots. They are then able to use these skills for addition and subtraction activities. The use of numbers and the execution of the arithmetic operations used in the third level are not generally one of the targeted objectives of the kindergarten curriculum but there are usually children who are able to work at this level.

At the ground or zero level, students are instructed to use various portable applications. In one of the applications, for example, they have to place a certain number of chicks in their nest or to count the number of animals that appear on the screen (Figure 3). Variables are randomized numbers from one to ten for each round.

The other tasks at hand are to help a climber pass over mountains, counting each mountain on the way and to a help a monkey down a ladder, counting each rung as it descends (Figure 4).

At the first level the children are expected respond to questions such as, "How many of the apples in her basket can Helen buy with 5 euro if each fruit costs 1 euro?” Another example problem is, "Each child needs a ticket to enter the castle. How many children will not be able to enter?” (Figure 5).

At the second level the children are asked to solve problems such as, "Place as many eggs as you would like in the fridge," after the selection is made the eggs are concealed. "Helen came and took 1 egg from the fridge. How many eggs are left?” (Figure 6).

Finally, for the third level applications, pupils are told to answer more complex questions such as, "Johnny has 5 pieces of candy. His uncle came and gave him some more candy. Now Johnny has 8 pieces of candy. How many pieces of candy did his uncle give him?” Alternatively, in the case of subtraction, the children are told that a monkey has cut a number of bananas from the tree. Some of his animal friends suddenly appear and
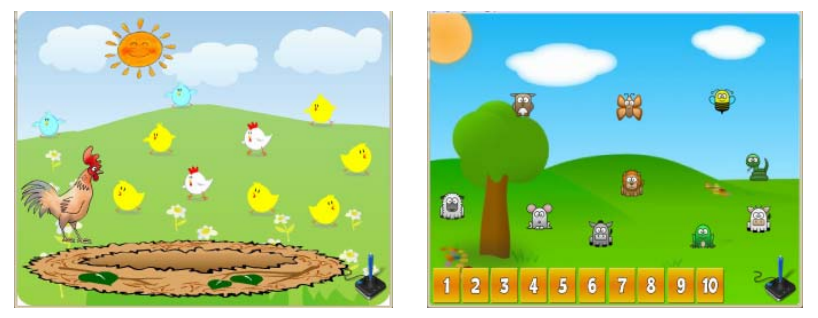

Figure 3.

Examples of ground level portable applications.
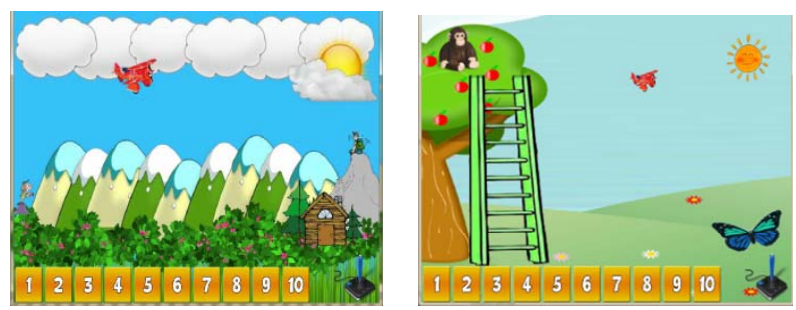

Figure 4.

Examples of ground level portable applications.
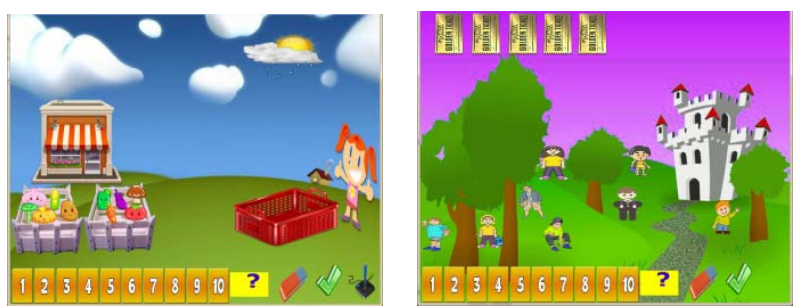

Figure 5.

Examples of first level portable applications.
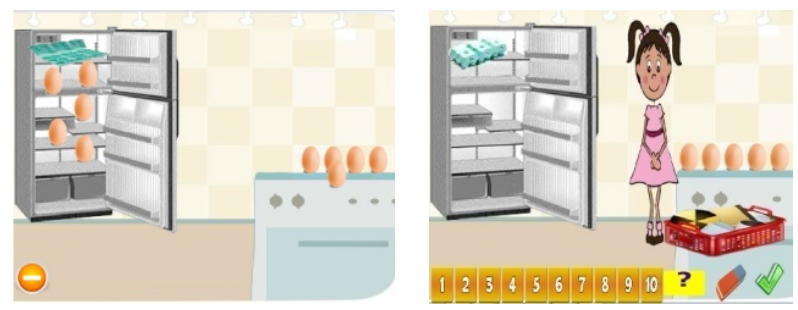

Figure 6.

Example of a second level portable applications.

eat an unknown number of those bananas. The remaining bananas are displayed and the children are asked to find the number of bananas that were eaten (Figure 7).

Considering the categorization of Naismith et al., (2004), we can claim that from a pedagogical point of view, the mobile applications we created follow either the behavioral or the constructivist teaching method. Some applications follow the behaviorist perspective by providing fast and immediate feedback while utilizing reinforcing learning elements like the confirmation of the correctness of an answer. Others utilize the constructivist perspective as they provide open type learning experiences for the students. All applications provide feedback both in the case of error as well as the successful completion of an activity. This feedback is in both visual and audible form so that it is easily understandable by pupils. Simple feedback is provided through graphic characters (e.g. the appearance of a happy or sad face), while more complex feedback is provided by the narrator through an audio message (e.g. "Try again,” or “Well done, you did it!”).

The applications were created using the application development software App Inventor (AI) and were tested on the Android operating system. Android was preferred over the iOS operating system (Apple) mainly because of its flexibility for the creation of applications as well as the existence of a very large variety of available devices with various price ranges and features. AI was first announced as a small project of Google Labs at the end of 2010. In late 2011, it was moved to the center of mobile learning in MIT (Massachusetts Institute of Technology) for public use as open source software (http:// appinventor.mit.edu/). AI is a new free online block based visual development environment for creating mobile applications of the Android operating system (Hsu et al., 2012).

The design process of the educational software had three main components:

- The research and development of the original applications prior to their implementation in kindergarten;

- The modification of the existing applications during the pilot test in order to respond more effectively to the needs of children and kindergarten educators; 

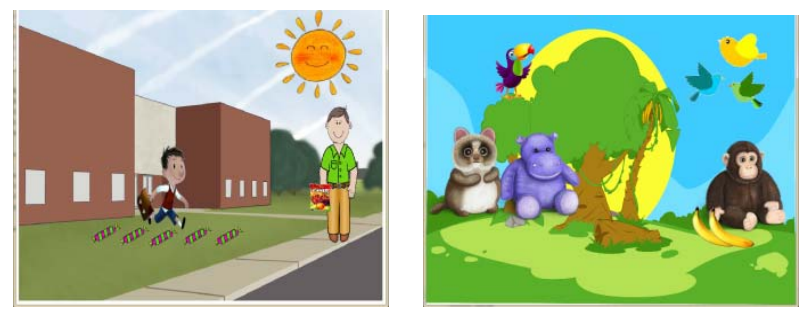

Figure 7.

Examples of third level portable applications.

- The creation of new applications that meet the demands of preschool educators.

The produced software should have the following characteristics: 1) It should be user-friendly so that children can easily handle it without any special assistance from an adult; 2) It should not require any reading and writing knowledge for its use so that it is suitable for the preschool age; 3) It should combine animation and sound. At the preschool age, sound is essential, as speaking is the only way to give instructions to children.

In order to examine the children's knowledge in the comparison, classification, matching, structured counting, efficient counting, basic addition and subtraction and general knowledge of numbers, we will most likely use the Utrecht Early Mathematical Competence Test (for children aged 4.00 - 7.05). This criterion was designed by a team of scientists from the department of special education at the University of Utrecht in the Netherlands, in order to be used for the assessment of early mathematical competence in preschool age children (4.06 - 7.05) (Van de Rijt, Van Luit, \& Pennings, 1999). In 2008, the weighting of this criterion in Greece led to the expansion of the age range for six months. We will use all of the worksheets from this test, because we assume that it is suitable for the purpose of our research.

\section{Conclusion}

As already mentioned, the purpose of this paper was to provide a better understanding of the characteristics and the effect of ICT and mobile learning in the context of preschool education. In addition, we will try to examine children's knowledge by comparing the learning outcomes of teaching using specially designed applications for smart mobile devices (tablets) and the thematic teaching in mathematics; specifically targeting "Realistic Mathematics", for children ages 4 to 6 years attending Greek kindergartens.

Although the research is still in a preliminary stage, initial results of the statistical analysis of pre tests (which were held in a small sample of kindergarten students in specific geographic regions of Greece) allow us to assume the following:

- The tablet aided learning compared to the traditional teaching method produces better learning outcomes for the students;

- The teaching of Realistic Mathematics with the use of educational software for tablets produces better learning outcomes in relation to teaching based on the Greek Cross Thematic Curriculum Framework (CTCF, 2003).

With great interest, we look forward to the learning outcomes that result from the teaching intervention using a large and properly weighted sample of kindergarten students. We intend to expand our research in kindergartens located in all geo- graphical regions of Greece in order achieve a larger possible representative sample distribution.

\section{Discussion}

Quite often, the debate on the use of ICT in mathematical education is limited by and focused on the tool itself rather than on the activities and in the specific problem situation that the student is presented. In contrast, the activities and applications that we have created refer to real world problems and situations. The next stage of the research will be carried out in kindergarten education in order to systematically evaluate the integration of ICT and its educational benefits compared to the traditional method of teaching.

This study is preliminary in its nature, as our research serves to demonstrate a potentially greatly beneficial installation of mobile learning in childhood education. With the execution of a systematic study, we believe that our findings will contribute to the acceptance that the positive effects derived from the use of mobile devices and ICT in kindergarten in general, do not exist only in the presence of a computer in the classroom, but also by the way in which the technology is used by teachers. The primary concern, therefore, is how to maximize the benefits of these new instruments in order to enhance, rather than hinder, children's ICT experiences for the benefit of learning.

\section{Acknowledgements}

This publication was supported by the Research Committee of University of Crete (ELKE) http://www.elke.uoc.gr/.

\section{REFERENCES}

Banister, S. (2010). Integrating the iPod Touch in K-12 education: Visions and vices. Computers in the Schools, 27, 121-131. doi:10.1080/07380561003801590

Bebell, D., Dorris, S., \& Muir, M. (2012). Emerging results from the nation's first kindergarten implementation of iPads. Research summary. Auburn: Auburn School Department.

Bolduc, J., \& Lefebvre, P. (2012). Using nursery rhymes to foster phonological and musical processing skills in kindergarteners. Creative Education, 3, 495-502. doi:10.4236/ce.2012.34075

Buchanan, R. (2010). Accessibility and the iPad: First impressions. http://atmac.org/accessibility-and-the-ipad-first-impressions

Chiong, C., \& Shuler C. (2010). Learning: Is there an app for that? Investigations of young children's usage and learning with mobile devices and apps. New York: The Joan Ganz Cooney Center at Sesame Workshop.

Christie, J. F., \& Johnson, J. (2009). Play and digital media. Computers in the Schools, 26, 284-289. doi:10.1080/07380560903360202

Chronopoulou, E., \& Riga, V. (2012). The contribution of music and movement activities to creative thinking in pre-school children. Creative Education, 3, 196-204. doi:10.4236/ce.2012.32031

Clements, D. H. (2000). From exercises and tasks to problems and projects: Unique contributions of computers to innovative mathematics education. Journal of Mathematical Behavior, 19, 9-47. doi:10.1016/S0732-3123(00)00036-5

Clements, D. H., \& Sarama, J. (2007). Early childhood mathematics learning. In: J. F. K. Lester (Ed.), Second handbook of research on mathematics teaching and learning (pp. 461-555). New York: Information Age Publishing.

Comaskey, M., Savage, S., \& Abrami, P. (2009). A randomised efficacy study of web based synthetic and analytic programmes among disadvantaged urban kindergarten children. Journal of Research in Reading, 32, 92-108. doi:10.1111/j.1467-9817.2008.01383.x

Common Core State Standards Initiative (2010). Common core state 
standards for mathematics.

http://www.corestandards.org/assets/CCSSI_Math\%20Standards.pdf

Common Sense Media (2011). Zero to eight: Children's media use in America.

http://www.commonsensemedia.org/sites/default/files/research/zerot oeightfinal2011.pdf

Couse, J., \& Chen, W. (2010). A tablet computer for young children? Exploring its viability for early childhood education. Journal of Research on Technology in Education, 43, 75-98.

CTCF (2003). Cross thematic curriculum framework. Published by the Greek Pedagogical Institute on the Government Gazette, Issue B.

De Lange, J. (1996). Using and applying mathematics in education. In: A.-J. Bishop, K. Clements, Ch. Keitel, J. Kilpatrick, \& C. Laborde (Eds.). International handbook of mathematics education (Part 1, pp. 49-97). Dordrecht: Kluwer Academic Publishers.

Druin, A., \& Fast, K. (2002). The child as learner, critic, inventor, and technology design partner: An analysis of three years of Swedish student journals. The International Journal for Technology and Design Education, 12, 189-213. doi:10.1023/A:1020255806645

Egan, M., \& Hengst, R. (2012). Software on demand: An early childhood numeracy partnership. Contemporary Issues in Technology and Teacher Education, 12, 328-342.

Federal Trade Commission (2012). Mobile apps for kids: Disclosures still not making the grade.

http://www.ftc.gov/os/2012/12/121210mobilekidsappreport.pdf

Finitsis, A. (2012). Rewired: Understanding the iGeneration and the way they learn-By Larry D. Rosen. Teaching Theology \& Religion, 15, 288-289. doi:10.1111/j.1467-9647.2012.00811.x

Freudenthal, H. (1983). Didactical phenomenology of mathematical structures. Dordrecht: Reidel.

Fuegen, S. (2012). The impact of mobile technologies on distance education. TechTrends, 56, 49-53. doi:10.1007/s11528-012-0614-0

Gadzichowski, K. (2012). Patterning abilities of first grade children: Effects of dimension and type. Creative Education, 3, 632-635. doi:10.4236/ce.2012.35092

Garrison, M., \& Christakis, D. A. (2005). A teacher in the living room: Educational media for babies, toddlers, and preschoolers. Menlo Park, CA: The Henry J. Kaiser Family Foundation.

Gelman, R., \& Meck, E. (1983). Preschoolers' counting: Principles before skill. Cognition, 13, 343-359. doi:10.1016/0010-0277(83)90014-8

Gjelaj, M. (2013). Effects of preschool education in preparing children for the first grade in terms of linguistic and mathematical development. Creative Education, 4, 263-266. doi:10.4236/ce.2013.44039

Haugland, S. W. (1999). What role should technology play in young children's learning? Young Children, 54, 26-30.

Hertzog, N., \& Klein, M. (2005). Beyond gaming: A technology explosion in early childhood classrooms. Gifted Child Today, 28, 24-31.

Hsu, Y. C., Rice, K., \& Dawley, L. (2012), Empowering educators with Google's Android App Inventor: An online workshop in mobile app design. British Journal of Educational Technology, 43, E1-E5. doi:10.1111/j.1467-8535.2011.01241.x

Johnson, L., Smith, R., Willis, H., Levine, A., \& Haywood, K. (2011). The Horizon Report 2011 Edition. Austin, TX: The New Media Consortium.

Jordan, N. C., Kaplan, D., Ramineni, C., \& Locuniak, M. N. (2009). Early math matters: Kindergarten number competence and later mathematics outcomes. Developmental Psychology, 45, 850-867. doi:10.1037/a0014939

Kagan, S., \& Scott-Little, C. (2004). Early learning standards: Changing the parlance and practice of early childhood education? Phi Delta Kappan, 85, 388-396.

Kenny, F., \& McDaniel, R. (2011). The role teachers’ expectations and value assessments of video games play in their adopting and integrating them into their classrooms. British Journal of Educational Technology, 42, 197-213. doi:10.1111/j.1467-8535.2009.01007.x

Klawe, M. (1999). Computer games, education and interfaces: The EGEMS project. In I. Scott MacKenzie, \& J. Stewart (Eds.), Proceedings of the Graphics Interface 1999 Conference (pp. 36-39), 2-4 June 1999, Kingston: Canadian Human-Computer Communications Society.
Klein, S., Nir-Gal, O., \& Darom, E. (2000). The use of computers in kindergarten, with or without adult mediation; effects on children's cognitive performance and behavior. Computers in Human Behavior, 16, 591-608. doi:10.1016/S0747-5632(00)00027-3

Klopfer, E., Squire, K., \& Jenkins, H. (2002). Environmental detectives PDAs as a Window into a virtual simulated world. IEEE International Workshop on Wireless and Mobile Technologies in Education, 95-98. doi:10.1109/WMTE.2002.1039227

Lam, J., \& Duan, G. (2012). A review of mobile learning environment in higher education sector of Hong Kong: Technological and social perspectives. In S. K. S. Cheung, J. Fong, L. for Kwok, K. Li, \& R. Kwan (Eds.), ICHL (pp. 165-173). Springer.

Lavidas, K., Komis, V., \& Gialamas, V. (2012). Spreadsheets as cognitive tools: A study of the impact of spreadsheets on problem solving of math story problems. Education and Information Technologies, 18, 113-129. doi:10.1007/s10639-011-9174-8

Lee, Y. (2009). Pre-K children's interaction with educational software programs: An observation of capabilities and levels of engagement. Journal of Educational Multimedia and Hypermedia, 18, 289-309.

Leoni, E. (2010). Apple's announcement of the new iPad: How will it affect education?

http://www.edutopia.org/apple-ipad-education?page $=1$

Lewin, C. (2000). Exploring the effects of talking books software in UK primary classrooms. Journal of Research in Reading, 23, 149157. doi:10.1111/1467-9817.00111

Lieberman, D., Bates, C., \& So, J. (2009a). Young children’s learning with digital media. Computers in the Schools, 26, 271-283. doi:10.1080/07380560903360194

Lieberman, D., Fisk, C. M., \& Biely, E. (2009b). Digital games for young children ages three to six: From research to design. Computers in the Schools, 26, 299-313. doi:10.1080/07380560903360178

Lindahl, G., \& Folkesson, A. (2012). ICT in preschool: Friend or foe? The significance of norms in a changing practice. International Journal of Early Years Education, 20, 422-436. doi:10.1080/09669760.2012.743876

Marsh, J. (2010). Young children's play in virtual worlds. Journal of Early Childhood Research, 8, 23-39. doi:10.1177/1476718X09345406

McManis, L., \& Gunnewig, S. (2012). Finding the education in educational technology with early learners. Young Children, 67, 14-25.

MDG advertising (2012). Kid tech according to apple [Infographic]. http://www.mdgadvertising.com/blog/kid-tech-according-to-apple-in fographic/

Musawi, A. (2011). Redefining technology role in education. Creative Education, 2, 130-135. doi:10.4236/ce.2011.22018

Naismith, L., Lonsdale, P., Vavoula, G., \& Sharples, M. (2004). Literature Review in Mobile Technologies and Learning: Report 11. Bristol: Futurelab.

NAYEC (1996). Technology and young children-Ages 3 through 8: A position statement of the national association for the education of young children. Washington DC: NAEYC.

Nix, J. (2005). The development of mobile learning for smartphones. Proceedings of IADIS International Conference Applied Computing, Algarve, 22-25 February 2005.

NPD Group (2008). Kids and consumer electronics IV. Port Washington, NY: NPD Group.

Orlando, J. (2012). Toddlers, touch screens and the parents' dilemma. http://www.theaustralian.com.au/news/features/toddlers-touch-screen s-and-the-parents-dilemma/story-e6frg6z6-1226238471750

Peluso, D. (2012), The fast-paced iPad revolution: Can educators stay up to date and relevant about these ubiquitous devices? British Journal of Educational Technology, 43, E125-E127. doi:10.1111/j.1467-8535.2012.01310.x

Plowman, L., \& Stephen, C. (2003). A “benign addition”? Research on ICT and pre-school children. Journal of Computer Assisted Learning, 19, 149-164. doi:10.1046/j.0266-4909.2003.00016.x

Plowman, L., \& Stephen, C. (2005). Children, play and computers in pre-school education. British Journal of Educational Technology, 36 , 145-158. doi:10.1111/j.1467-8535.2005.00449.x

Plowman, L., Stephen, C., \& McPake, J. (2010). Supporting young children's learning with technology at home and in preschool. $R e$ - 
search Papers in Education, 25, 93-113.

doi:10.1080/02671520802584061

Prensky, M. (2001). Digital game-based learning. New York: McGraw Hill.

Prensky, M. (2010). Teaching digital natives: Partnering for real learning. Thousand Oaks: Corwin.

Rushton, S. (2008). Classroom learning environment, brain research and the no child left behind initiative: Six years later. Early Childhood Education Journal, 36, 87-92. doi:10.1007/s10643-008-0244-5

Rushton, S., \& Larkin, E. (2001). Shaping the learning environment: Connecting developmentally appropriate practices to brain research. Early Childhood Education Journal, 29, 25-33.

doi:10.1023/A:1011304805899

Rushton, S., Juola, A., \& Larkin, E. (2009). Neuroscience, play, and early childhood education: Implications, connections and assessment. Early Childhood Education Journal, 37, 351-361. doi:10.1007/s10643-009-0359-3

Sadowski, M. (2006). The school readiness gap. Harvard Education Letter, 22, 4-7.

Sandvik, M., Smørdal, O., \& Østerud, S. (2012). Exploring iPads in practitioners' repertoires for language learning and literacy practices in kindergarten. Nordic Journal of Digital Literacy, 7, 204-221.

Segers, E., \& Verhoeven, L. (2003). Effects of vocabulary training by computer in kindergarten. Journal of Computer Assisted Learning, 19, 557-566. doi:10.1046/j.0266-4909.2003.00058.x

Shaffer, W., Squire, R., Havelson, R., \& Gee, P. (2005). Video games and the future of learning. Phi Delta Kappan, 87, 104-111.

Sharples, M., Taylor, J., \& Vavoula, G. (2007). A theory of learning for the mobile age. In R. Andrews, \& C. Haythornthwaite (Eds.), The Sage handbook of e-learning research (pp. 221-247). London: Sage. doi:10.4135/9781848607859.n10

Shuler, C. (2009). Pockets of potential: Using mobile technologies to promote children's learning. New York: The Joan Ganz Cooney Center at Sesame Workshop.

Somekh, B. (2007). Pedagogy and Learning with ICT: Researching the art of innovation. London and New York: Routledge.

Squire, K. (2006). From content to context: Videogames as designed experience. Educational Researcher, 35, 19-29. doi:10.3102/0013189X035008019

Squire, K., \& Jenkins, H. (2003). Harnessing the power of games in education. Insight, 3, 5-33.

Starkey, P., Klein, A., \& Wakeley, A. (2004). Enhancing young children's mathematical knowledge through a pre-kindergarten mathematics intervention. Early Childhood Research Quarterly, 19, 99120. doi:10.1016/j.ecresq.2004.01.002

Streefland, L. (1991). Fractions in realistic mathematics education. A paradigm of developmental research. Dordrecht: Kluwer Academic Publishers. doi:10.1007/978-94-011-3168-1

Swing, E. L., \& Anderson, C. A. (2008). How and what do video games teach? In T. Willoughby, \& E. Wood (Eds.), Children's learning in a digital world (pp. 64-84). Oxford: Blackwell.

Thorell, B., Lindqvist, S., Bergman, S., Bohlin, G., \& Klingberg, T. (2009). Training and transfer effects of executive functions in preschool children. Developmental Science, 12, 106-113. doi:10.1111/j.1467-7687.2008.00745.x
Tzekaki, M. (2007). Small kids, great mathematical meanings. Athens: Gutenberg.

Van de Rijt, B. A. M., Van Luit, J. E. H., \& Pennings, A. H. (1999). The construction of the Utrecht early mathematical competence scale. Educational and Psychological Measurement, 59, 289-309.

Van den Heuvel-Panhuizen, M. (2008). Children learn mathematics: A learning-teaching trajectory with intermediate attainment targets for calculation with whole numbers in primary school. Rotterdam/Tapei: Sense Publishers.

Vavoula, G., \& Karagiannidis, C. (2005). Designing mobile learning experiences. In P. Bozanis, \& E. N. Houstis (Eds.), PCI 2005, LNCS 3746 (pp. 534-544). Berlin: Springer-Verlag.

Vavoula, G., Pachler, N., \& Kukulska-Hulme, A. (2009). Researching mobile learning: Frameworks, methods and research designs. Oxford: Peter Lang.

Verenikina, I., \& Kervin, L. (2011). iPads, digital play and pre-schoolers. Не Кири, 2, 4-16.

Voithofer, R. (2005). Designing new media education research: The materiality of data, representation and dissemination. Educational Researcher, 34, 3-14. doi:10.3102/0013189X034009003

Wakefield, J., \& Smith, D. (2012). From socrates to satellites: iPad learning in an undergraduate course. Creative Education, 3, 643-648. doi:10.4236/ce.2012.35094

Yelland, N. (1998). Empowerment and control with technology in the early childhood years. Educational Practice and Theory, 20, 45-55. doi:10.7459/ept/20.2.05

Yelland, N. (2002). Playing with ideas and games in early mathematics. Contemporary Issues in Early Childhood, 3, 197-215. doi:10.2304/ciec.2002.3.2.4

Yelland, N. (2005). The future is now: A review of the literature on the use of computers in early childhood education (1994-2004). AACE Journal, 13, 201-232.

Zaranis, N. (2011). The influence of ICT on the numeracy achievement of Greek kindergarten children, In A. Moreira, M. J. Loureiro, A. Balula, F. Nogueira, L. Pombo, L. Pedro, \& P. Almeida (Eds.) Proceedings of the 61st International Council for Educational Media and the XIII International Symposium on Computers in Education (ICEM\&SIIE'2011) Joint Conference (pp. 390-399), University of Aveiro, Portugal, 28-30 September 2011.

Zaranis, N. (2012). The use of ICT in Preschool Education for geometry teaching. In R. Pintó, V. López, \& C. Simarro (Eds.), Proceedings of the 10th International Conference on Computer Based Learning in Science, Learning Science in the Society of Computers (pp. 256-262). Centre for Research in Science and Mathematics Education (CRECIM), Barcelona, 26-29 June 2012.

Zaranis, N., \& Kalogiannakis, M. (2011a). The use of ICT in preschool education for science teaching with the Van Hiele theory, In M. F. Costa, B. V. Dorrío, \& S. Divjak (Eds.) Proceedings of the 8th International Conference on Hands-on Science (pp. 21-27), University of Ljubljana, Slovenia, 15-17 September 2011.

Zaranis, N., \& Kalogiannakis, M. (2011b). Greek primary students' attitudes towards the use of ICT for teaching natural sciences, In M. F. Costa, B. V. Dorrío, \& S. Divjak (Eds.), Proceedings of the 8th International Conference on Hands-on Science (pp. 50-55), University of Ljubljana, Slovenia, 15-17 September 2011. 